\title{
A Study to Evaluate the Efficacy of the Prognosis of Mannheim Peritonitis Index Score in Patients with Perforation Perotinitis
}

Authors

\section{Dr Anurag Singh, MBBS, MS; Dr Mushtaq Ali*, MBBS, MS, FIAGES*; Dr S.K. Bhat, MBBS, MS; Dr Osman Musa, MBBS,MS; Dr Rahul Agrawal, MBBS, MS \\ *Corresponding Author \\ Mushtaq Ali \\ Asst. Prof. Era Medical College, Sarfarazganj, Lucknow, India \\ Email: jenabpehleaap@gmail.com}

\section{Introduction}

Peritonitis caused by hollow viscous perforation continues to be one of the most challenging conditions confronted by a surgeon. It is one of the frequently encountered surgical emergencies in tropical countries like India and most of the times it affects young males in the productive phase of their life $\mathrm{e}^{1,2,3,4}$.

Peritonitis following perforation of the gastrointestinal tract remains an important problem in the field of abdominal surgery. The clinical symptoms of peritonitis vary depending largely on the site of perforation as the contents and / or bacterial flora are not uniform throughout the gastrointestinal tract and thus the therapy for peritonitis should always been based on such facts. By now it has been established that the spectrum of etiology of perforation in Indian subcontinent differs from its western counterpart ${ }^{2}$. Majority of the patients present late, with purulent peritonitis and septicemia ${ }^{5}$. Surgical treatment of perforation peritonitis is highly demanding and very complex, combination of improved surgical technique, anti microbial therapy and intensive care support has improved the outcome of such cases ${ }^{6}$.

Although, a number of advancements have been made in surgical techniques, antimicrobial therapy and intensive care support yet management of peritonitis continues to be highly demanding, difficult and complex. Consecutively, the prognosis of patients with perforation peritonitis and intra-abdominal infections is generally poor ${ }^{7}$. Perforation peritonitis might be responsible for multi organ failure, thus increasing the severity of morbidity and mortality ${ }^{8}$.

Interestingly, there has been seen to be differences in the location of perforation in different geographical regions across the world. In eastern countries such as India and Pakistan, the proximal part of the gastrointestinal tract (GIT) is affected more commonly ${ }^{2}$ whereas in western population distal gut perforation is more common. Overall, duodenum is the most common site of perforation ${ }^{9}$. 
In majority of cases the presentation to the hospital is late with well established generalized peritonitis with purulent/fecal contamination and varying degree of septicemia. The signs and symptoms are typical and it is possible to make a clinical diagnosis of peritonitis in all patients ${ }^{2}$. Moreover, complex nature of surgical infections, the multifaceted aspects of treatment, and the complexity of Intensive Care Unit (ICU) support makes evaluation of new diagnostic and therapeutic advances in this field very difficult ${ }^{10}$.

One of the reasons for difficulty in predicting the outcome is lack of precise classification. Keeping in view this difficulty, need for a scoring system to quantify the severity of perforation peritonitis and to predict the outcome has been felt.

Although, several scoring systems have been proposed to stratify the patients with peritonitis. Some of these scoring systems include: Peptic Ulcer Perforation (PULP) score, Acute Physiology and Chronic Health Evaluation, BOEY score, Simplified acute physiology score (SAPS), Sepsis severity score (SSS), Ranson score, Imrie score and Manheim peritonitis index (MPI) 11,12,13,14,15, 16,17 .

Among various scoring systems available, Manheim peritonitis index (MPI) was developed by Wacha and Linder in 1983. It was based on the retrospective analysis of data from 1253 patients with peritonitis, in which 20 possible risk factors were considered. Of these only 8 proved to be of prognostic relevance and were in entered into the Manheim Peritonitis Index, classified according to their predictive power ${ }^{18}$.

The MPI is a specific score, which has a good accuracy and provides an easy way to handle with clinical parameters, allowing the prediction of the individual prognosis of patients with peritonitis ${ }^{19}$. The wide applicability, validity and reliability of MPI is regarded even nearly four decades after its introduction ${ }^{7,10,20}$. Considering its wide usage throughout the world, in present study we also make an attempt to evaluate Mannheim Peritonitis
Index score for predicting the outcome in patients with perforation peritonitis.

\section{Aim}

Evaluation of Mannheim Peritonitis Index score for predicting the outcome in patients with perforation peritonitis

\section{Objectives}

- To evaluate the patients with perforation peritonitis on MPI.

- To compare the pre and intra operative MPI with post operative outcome.

- To study how effective is MPI in predicting outcome in patients with perforation peritonitis.

\section{Material and Methods}

Prospective study of 49 patients admitted and operated for perforation peritonitis in Era's Lucknow Medical College \& Hospital. The structured scoring system i.e. MPI was applied along with other clinical and biochemical parameters recorded in pre-structured proforma. Data was analysed for predicting mortality and morbidity using EPI info and SPSS software.

\section{Results}

The present study was conducted to evaluate Mannheim Peritonitis Index score for predicting the outcome in patients with perforation peritonitis. Out of patients presenting to surgery OPD or Emergency with clinical features of perforation peritonitis, 48 patients confirmed on clinical and radiological evaluation were included in the study. Following results were observed:

1) Age of patients ranged from 18 to 68 years, mean age was $41.52 \pm 12.74$ years, only $25.0 \%$ patients were aged $>40$ years. Majority of the patients enrolled in the study were males $(70.8 \%)$.

2) Most common presenting symptoms of patients were distension (97.9\%), constipation $(95.8 \%)$ and abdominal pain $(87.5 \%)$ while 
less common presenting symptoms were Fever (66.7\%), Vomiting (45.8\%) and Flatus (2.1\%). Gastric site perforation was most common $(54.2 \%)$, other common sites were Ileal (18.8\%), Appendicular (16.7\%).

3) All the patients enrolled had non-colonic sepsis and generalized extension of peritonitis. Malignancy was found in only 1 $(2.1 \%)$ while organ failure was reported among $2(4.2 \%)$ cases. Clear exudate was found in majority of the cases (56.3\%), exudate was purulent and fecal among $18.8 \%$ and $25.0 \%$ cases respectively.

4) Mannheim Peritonitis Index (MPI) score of majority of the cases enrolled in the study was $\leq 20(56.3 \%)$, only $6.3 \%$ cases had MPI score $\geq 30$.

5) Out of 48 cases enrolled in the study $4(8.3 \%)$ expired during the treatment, rest $44(91.7 \%)$ were discharged after treatment. Average duration of hospital stay was $12.22 \pm 2.12$ days (Range 8-18 days).

6) Association of outcome with various factors of Mannheim Peritonitis Index score was found to be statistically significant only with Age $>50$ years, Organ failure and Malignancy, incidence of above factors was significantly higher among expired patients as compared to discharged.

7) MPI $\geq 30$ was found to be $50.0 \%$ sensitive and $97.7 \%$ specific for outcome mortality but no significant association of MPI score with duration of hospital stay was observed.

\section{Conclusion}

The present study showed usefulness of MPI in stratification of mortality risk among patients waiting surgical intervention for perforation peritonitis. An increasing MPI score is indicator of an increased mortality. The component scores might help the healthcare providers to prepare adequate strategies to address the individual specific treatment needs in order to improve the outcome.

\section{References}

1. Dorairajan LN, Gupta S, Deo SV, Chumber S, Sharma LK. Perotinitis in India: A decade experience. Tropical Gastroenterol. 1995;16:33-8.

2. Sharma L, Gupta S, Soin AS, Sikora S, Kapoor V. Genaralised peritonitis in India - tropical spectrum. Jpn J Surg. 1991;21:272-7.

3. Jhobta RS, Attri AK, Kaushik R, Sharma $\mathrm{R}$, Jhobta A. Spectrum of perforation peritonitis in India: A review of 504 consecutive cases. World J Emerg Surg. 2006;1:26.

4. Gupta S, Kaushik R. Peritonitis: The eastern experience. World J Emerg Surg. 2006; $1: 13$.

5. Ersumo T, W/MESKEL y, Kotisso B: Perforated peptic ulcer in Tikur Anbessa Hospital; a review of 74 cases. Ethiop Med J 2005, 43(1):9-13.

6. Bosscha K, van Vroonhoven TJ, Werken $\mathrm{C}$ van der: Surgical management of severe secondary peritonitis. Br J Surg 1999, 86(11):1371-7.

7. Rangaswamy P, Rubby SA, Prasanna CM. Clinical study of perforative peritonitis and the role of mannheim peritonitis index in predicting its mortality. Int Surg J. 2016 Nov;3(4):2016-2021.

8. Bohnen J, Boulenger M, Mackin JL. Prognosis in generalized peritonitis, relation to cause and risk factors. Arch Surg. 1983;118:285-90.

9. Melangoni MA, Inui T. Peritonitis: The western experience. World J Emerg Surg. 2006; 1:25.

10. Sharma S, Singh S, Makkar N, Kumar A, Sandhu MS. Assessment of Severity of Peritonitis Using Mannheim Peritonitis Index. Nigerian Journal of Surgery: Official Publication of the Nigerian Surgical Research Society. 2016;22(2):118-122. 
11. Irvin TT. Mortality and perforated peptic ulcer: a case for risk stratification in elderly patients. Br J Surg. 1989;76:21518.

12. Moller MH, Engebjerg MC, Adamsen S, Bendix J, Thomsen RW. The Peptic Ulcer Perforation (PULP) score: a predictor of mortality following peptic ulcer perforation. A cohort study. Acta anaesthesiologica Scandinavica. 2012;56(5):655-62.

13. Moller MH, Adamsen S, Thomsen RW, Moller AM. Preoperative prognostic factors for mortality in peptic ulcer perforation - a systematic review. Scand J Gastroenterol. 2010;45:785-805.

14. Moller MH, Shah K, Bendix J, Jensen AG, Zimmermann-Nielsen E, Adamsen $\mathrm{S}$, Moller AM. Risk factors in patients surgically treated for peptic ulcer perforation. Scand J Gastroenterol. 2009; 44:145-52.

15. Knaus WA, Zimmerman JE, Wagner DP, Draper EA, Lawrence DE. APACHE-acute physiology and chronic health evaluation: a physiologically based classification system. Critical Care Medicine. 1981:9.

16. Boey J, Choi SKY, Alagaratnam TT, Poon A. Risk stratification in perforated duodenal ulcers. Ann Surg. 1987;205:226.

17. Bion J. Outcome in Intensive care. BMJ. 1993;307:953-54.

18. Linder MM, Wacha H, Feldmann U, Wesch G, Streifensand RA, Gundlach E. [The Mannheim peritonitis index. An instrument for the intraoperative prognosis of peritonitis] Chirurg. 1987;58(2):84-92.

19. Bosscha K, Reijnders K, Hulstaert PF, Algra A, van der Werken C. Prognostic scoring systems to predict outcome of peritonistis and inta- abdominal sepsis. $\mathrm{Br}$ J Surg. 1997; 84(11):1532-34.
20. Kumar P, Singh K, Kumar A. A comparative study between Mannheim peritonitis index and APACHE II in predicting the outcome in patients of peritonitis due to hollow viscous perforation. Int Surg J. 2017 Feb;4(2):690696. 